\title{
HUMANISMO Y CONOCIMIENTO. MARCUSE CONTRA DRUCKER
}

\author{
Humanism and Knowledge. Marcuse against Drucker \\ Adolfo Lizagarra Gómez \\ Universidad Michoacana de San Nicolás de Hidalgo \\ alizarragag@yahoo.com.mx
}

\begin{abstract}
Resumen:
En este artículo se contrapone el concepto de "sociedad del conocimiento" de Peter Drucker al de humanitas de Herbert Marcuse con el fin de debatir la concepción dominante de educación en la actualidad que impone la tecnificación sobre las humanidades. El tema central es el sentido que esa educación tecnicista da a las necesidades, el trabajo y el desarrollo tecnológico, que es el de deshumanización del trabajo humano. Primero, se expone el concepto de "saber" de Drucker, a continuación, el de humanitas de Marcuse y finalmente se hacen algunas notas conclusivas que tocan la contraposición entre ambas teorías.
\end{abstract}

Palabras clave:

Humanismo, Drucker, Marcuse, conocimiento, tecnología

\begin{abstract}
:
In this paper is counterposed the Peter Drucker's concept of "knowledge society" to the Marcuse's humanitas one to debate the nowadays dominate conception of education, that impose technification over humanities. The central issue is the sense that this technicist education gives to necessities, work and technological development: the dehumanization of human work. First, it is expose the concept of "knowledge", then the Marcuse's one of humanitas and finely it is give some conclusive notes over the counterposition between both theories.
\end{abstract}

\section{Keywords:}

Humanism, Drucker, Marcuse, Knowledge, Technology

Recibido: 03/11/2019

Aceptado: 11/12/2019 


\section{INTRODUCCIÓN}

El autor austriaco Peter Drucker acuñó a fines de la década de 1960 el concepto de "sociedad del conocimiento" que la UNESCO adoptó como un modelo para el desarrollo de los "países del sur" y las "economías emergentes" (UNESCO, 2005: 20 y ss.), sobre el supuesto de que no existe otra alternativa para la solución de sus problemas sociales, en particular, el de la pobreza. El concepto de Drucker se refiere al desarrollo tecnológico que, según ese autor, es el eje y fundamento de la historia de la sociedad moderna capitalista. Algunos estudios recientes, han sugerido que ese concepto-propuesta efectivamente forma parte de la historia de algunos países que luego se ha convertido en una aspiración para otros, como los de América Latina (CEPAL 2018). Pero no se repara en que el concepto de Drucker pueda estar fundamentado en una historia en la que se impone lo que Marx denominó "trabajo enajenado", que consiste no sólo en el total despojo de las personas de su trabajo y sus productos, sino también de sus sentimientos, intereses, gustos y sentidos. Este artículo busca subrayar este hecho, contraponiendo al concepto de Drucker el de humanitas que aparece en diversas obras de Herbert Marcuse, y que ayuda a ese autor a poner en el centro de la teoría crítica a la educación tecnologizada en la era capitalista, el componente humano.

Precisamente, Drucker erige su teoría criticando a Marx y en la actualidad ha ganado reconocimiento como "gurú del Management" (Fernández, 2008; Puell, 2009; UNESCO, 2015: 4 y ss.; Hesselbein, 2016, Mansell, 2018, entre otros). Desde esa visión pro-empresarial, Drucker pudo acuñar el concepto estratégico para el tipo de educación para el desarrollo que la UNESCO, al parecer, andaba buscando. Cabe mencionar que ese organismo internacional adoptó el concepto de Drucker y luego lo matizó con el apoyo de autores posteriores, en particular, Robin Mansell y Nico Stehr, enfatizando el papel del desarrollo tecnológico como proveedor de información fundamental para conseguir los objetivos del "presente": la creación y manejo de productos tecnológicos, impulsando a que la enseñanza, conforme a cada situación, sea dirigida a alcanzar esos objetivos (UNESCO, 2008: 17 y ss.; 2005: 20 y ss.; Mansell, 2018: 10).

Por su parte, al analizar el desarrollo tecnológico, Marcuse hace referencia al concepto de humanitas, sin que se detenga específicamente en él, pero al relacionarlo con el de "trabajo enajenado", adquiere un lugar central en su teoría y otorga un rol destacado a la educación en la vida social. Drucker hace referencia críticamente al concepto de humanitas cuando habla de la "educación en la antigüedad", pero evita mencionarlo por su nombre. Así, los conceptos de humanitas y de "sociedad del conocimiento", nos permiten hacer un análisis crítico de la educación que domina hoy en día y que impone la educación tecnológica.

Cabe señalar, también, que la obra de Marcuse, al igual que la de Drucker, cobra relevancia en la década de 1960, sobre todo durante los movimientos estudiantiles de esos años. Ambas teorías, además, coinciden en que surgen en tiempos en que la industrialización y el desarrollo tecnológico se conciben como fundamento del desarrollo social incluso en países que se reclamaban como socialistas, como la Unión Soviética (Korsch, 1975: 42-51 y 204-221), y también posibilitó el surgimiento de 
nuevas potencias económicas, como Japón y de otros que son considerados "países emergentes", como la India y China (Mattick, 1978: 135-148).

El problema que plantea este artículo no es el desarrollo tecnológico, sino su sentido. Drucker y Marcuse oponen dos visiones radicalmente diferentes, que describen una confrontación entre el sentido mercantil e inhumano de la tecnología y el humanista y, en esa confrontación, media una concepción sobre las necesidades y su satisfacción. En tal sentido, en este artículo se expone, primero, la teoría de Drucker, por ser la que retoma la visión dominante sobre el desarrollo social en la actualidad, cuyo ejemplo es la UNESCO. A continuación, se expone la teoría de Marcuse, que critica el desarrollo tecnológico y la educación que tiene lugar sobre bases capitalistas liberales. Finalmente, se hacen unos comentarios conclusivos, que subrayan la contraposición de ambas visiones, destacando la intención de dirigir la vida humana rumbo a la humanidad misma, según lo sugiere la teoría crítica de Marcuse.

\section{DRUCKER Y LA IN-HUMANA "SOCIEDAD DEL SABER"}

\section{A. "SABER" Y "POST-CAPITALISMO"}

En su Drucker (1999), ese autor se dirige contra las teorías económicas que tratan sobre el desarrollo del capitalismo y, en particular, contra la obra de Karl Marx. Para ello, hace uso de los conceptos de "saber" y de "tecnología", el primero se expresa en el segundo. Pero el concepto de "saber" en Drucker, remite a una forma particular de enajenación e "inhumanismo", pues ese autor austriaco concibe el "saber" expresado en máquinas y productos creados para la satisfacción de demandas sociales, productivistas y mercantiles, y no para su productor y propietario original: el individuo humano. En este trabajo trataremos sobre esa sobreposición de necesidades en este concepto de "saber" de Drucker, para lo cual es preciso iniciar tratando de responder a la pregunta de en dónde se esconde lo inhumano de ese concepto'. La respuesta es: en su sentido enajenado y enajenante.

Drucker le da sentido inhumano a su concepto de "saber" de una manera aparentemente inconsciente pues, primero, asegura que la "sociedad del saber" no es la capitalista y, en segundo lugar, que esa "sociedad" es una utopía. Por ello, Drucker se ve precisado a explicar -sin lograrlo, como veremos- en dónde se ubica históricamente su teoría, para lo cual plantea, entonces, el concepto de "postcapitalismo" nombre que le da a la época social fundada en el desarrollo del "saber" y de la "tecnología". De la unidad de uno y otra derivan la "productividad" y la "innovación", que luego de la aplicación "del saber al trabajo" adquieren en aquel desarrollo el valor social máximo.

Según Drucker, la evolución histórica del "saber" que lleva al post-capitalismo, tiene tres fases. La primera, es cuando el "saber", por medio de su aplicación, se convierte en "hacer" y deja de ser una propiedad privada-individual para pasar a ser

1 El inglés el término es "knowledge", el cual, en general, se ha traducido como "conocimiento", salvo en algunos casos, como en la edición en español de Drucker (1999) que utilizamos para este artículo, que se traduce como "saber", y que nos parece más adecuado para los propósitos de este trabajo. 
cada vez más una propiedad pública que se expresa en herramientas y procesos de trabajo y, en consecuencia, también en productos más desarrollados. Esta fase del "saber-hacer", según Drucker, terminaría en 1880 (aunque no dice cuándo inicia). La segunda fase, tiene lugar en el "trabajo" y propició que el "proletario" pasara a ocupar el lugar del burgués, dada la cantidad de ingresos que el progreso del "saber" le permite alcanzar y, por este hecho, queda clausurada la lucha de clases y "el comunismo" que, según Drucker, fueron concebidos por Marx. Esta fase -sin que Drucker lo mencione-, habría terminado en la Segunda Guerra Mundial y se abre la tercera fase en la que, ahora, el "saber" cobra independencia, pues, dice Drucker: "el saber se aplica al saber mismo". A esta última fase Drucker la llama de "la gestión" y constituiría el arribo de la "sociedad del saber". En esta última fase el "saber" desplazaría "al capital y a la mano de obra" y se iniciaría la nueva época, a la que él llama "post-capitalista".

Recurriendo a esta historia del "saber", Drucker se siente en condiciones de enfrentar a las teorías económicas y en particular a la de Marx (Drucker, 1999: 17), aunque al final de su libro capitula a juzgar por la siguiente afirmación: "El capitalismo había sido la fuerza dominante durante un siglo cuando Karl Marx lo identificó por primera vez en Das Kapital ... como un orden social distinto... Sería, por lo tanto, no sólo presuntuoso en extremo intentar escribir El saber hoy, sería ridículamente prematuro" (Drucker, 1999: 268). Es decir, en realidad su teoría de la "sociedad del saber", no le parece suficiente para decretar el arribo de una época diferente a la capitalista. Drucker se da cuenta de lo impreciso de la serie de planteamientos que hace en su libro porque, en primer lugar, los declara como fenómenos azarosos, sin conexión unos con otros, pero confía en que ellos se pueden unir por sí solos para formar un sistema, tal como habría ocurrido con el capitalismo, gracias a que los fenómenos que él dice descubrir son destacadamente tecnológicos y la tecnología, según él, permite a cualquier sistema imponerse de manera rápida y amplia, pues produce cambios que se suceden cada vez con mayor rapidez. Drucker se dice seguro de que la tecnología, permitirá la emergencia de una "sociedad del saber", es decir, "post-capitalista".

En suma, la conclusión a la que llega Drucker es que la historia social no es la de la "lucha de clases" marxiana, sino la del "saber" expresado en tecnología. En este sentido, tratando de fortalecer su tesis, Drucker caracteriza la historia social, ahora no en tres, sino en cuatro etapas, cuyo eje transversal es el "saber": 1. La conformación del significado del "saber" en el tiempo; 2. El desarrollo tecnológico, que habría iniciado como una revolución industrial y expresa la emergencia del "saber" que se dirige rumbo a alcanzar un nivel privilegiado en la sociedad; 3 . La revolución en la productividad, como fase avanzada de la anterior, y, 4. La llegada a la "sociedad del saber", o "el saber aplicado al saber mismo", que impone el cambio radical entre la sociedad capitalista y la "post-capitalista". Si ha de existir en esta época todavía una sociedad dividida en clases, esta división se daría en función de la tecnología, pues la sociedad gira en torno al uso de los adelantos técnicos, ya sea en los diferentes procesos de producción individuales, como consumo productivo, ya en otras formas de expresión, como las artísticas, las arquitectónicas, en el vestido, etc., que, a la vez, se convierten en base y "vehículos" de la innovación constante y se conforma una nueva cultura que desarrolla "el saber aplicado al saber mismo". La pregunta cuya 
respuesta sigue pendiente es ¿qué habrá de entenderse por "saber"? Este es el tema del siguiente apartado.

\section{B. El SIGNIFICADO DEL "SABER" Y SU DES-HUMANIZACIÓN}

Para exponer el significado de su concepto de "saber", Drucker hace una comparación histórica. Afirma que el primer saber proviene de la antigua Grecia y que éste se refiere al saber individual, sólo en la modernidad el saber se impone como normalidad y se difunde para que pueda ser apropiado por otros, mediante la práctica y no mediante palabras o por la teoría: la modernidad ha desarrollado el saber mediante la conversión de la técnica en tecnología, esto quiere decir: la aplicación pública de los saberes, trascendiendo los espacios cerrados e institucionalizados, como la escuela, y aplicados en la creación y desarrollo de herramientas, productos y procesos productivos. La participación institucional en este proceso de "aplicación de saberes", se limita a la creación de normas y leyes que posibiliten la publicación del saber, que ahora pasa a ser "proceso de innovación" útil para la sociedad.

Por otra parte, el desarrollo tecnológico, según Drucker, clausuró la posibilidad del derrumbe del capitalismo, como lo habría anunciado Marx en el libro tercero de $E /$ capital, pues eliminó la crisis, lo cual se reflejaría en, al menos, dos hechos. Por una parte, la necesidad cada vez mayor de invertir más capital en herramientas, materiales, espacios adecuados, energía, mano de obra, etc., y elevando los ingresos de los obreros, conjurándose, así, la lucha de clases capitalista, a la vez que tiene lugar una revolución de los procesos productivos y de la productividad. Según Drucker, este constituye un hecho radical, pues, por una parte, le va transfiriendo al trabajador el poder real del sistema capitalista, en tanto que el "saber" está de su lado. Ahora la pregunta fundamental es ¿cómo se aplicará el saber a la producción?, y el problema es definir qué saber se producirá o deberá producirse. Este es el punto de llegada de la imposición de una "sociedad del saber", y es al que Drucker Ilama "etapa de gestión" y "post-capitalismo". Llegada esta etapa, el objetivo ahora es la innovación, identificando saber con acción, y la "información enfocada a resultados". Aquí inicia la cuestión principal: un proceso de enajenación que Drucker omite mencionar en sus términos.

Para él los "resultados están fuera de la persona, en la sociedad y la economía, o en el fomento del saber mismo". Y concluye: "Para conseguir algo este saber tiene que ser altamente especializado; esta es la razón por la cual la tradición que empezó con los antiguos pero que persiste en lo que llamamos 'educación humanista', lo relegaba al estatus de techne o arte. No podía ni aprenderse ni ser enseñado; tampoco significaba cualquier principio general; era específico y especializado; era experiencia más que instrucción, aprendizaje más que enseñanza. Sin embargo, hoy no hablamos de esos saberes especializados como 'artes', hablamos de 'disciplinas'. Y esto es un cambio muy importante en la historia intelectual" (Drucker, 1999: 62-3). Drucker no lo dice, pero se refiere aquí a la Paideia y la humanitas, tema que trataremos más adelante con Marcuse, y que tienen una relación estrecha con un concepto de humanidad del que Drucker pretende desprender al concepto de "saber".

Por lo pronto, para los propósitos de este artículo, de esta afirmación de Drucker pueden destacarse al menos tres momentos que definen su concepto de "saber". 
Primero, que el "saber" adquiere independencia, se convierte en algo exterior a la persona, pues ésta transfiere esa propiedad al "público". Segundo, la superación de este "saber", pasa por encima del sentido humanista, del que le había dotado el pensamiento antiguo, como propio de los individuos y seres humanos. Y, tercero, a diferencia del pensamiento antiguo griego, más que un arte u oficio, el "saber" se especializa en una disciplina. Pero esta enajenación de la persona en la sociedad y la deshumanización del "saber" convertido ahora en "disciplina" no queda claro si forma parte del capitalismo o de lo que Drucker concibe como "post-capitalismo". El planteamiento de Drucker es suficiente para que sus adeptos se concentren en el progreso tecnológico que, actualmente, es puesto en cautiverio por la concepción liberal como analizaremos a continuación siguiendo la obra de Marcuse.

\section{MARCUSE Y SU CRÍTICA AL HUMANISMO Y LA EDUCACIÓN LIBERALES}

Aunque la obra de Marcuse, al igual que la de Drucker, adquiere mayor reconocimiento, sobre todo, en la década de 1960, su origen crítico, comienza desde la década de 1930, cuando se une a la llamada "Escuela de Fráncfort" (Jay, 1989; Romero, 2016; Magnet, 2018).

Como vimos, Drucker se refiere a la adquisición del "saber" en los procesos productivos y fuera de la escuela, a la que concibe sólo como espacio institucional. La "sociedad del saber" y "post-capitalista", queda instaurada cuando el "saber se aplica al saber mismo", en términos prácticos y expansivos en la sociedad, convirtiéndose, así, en proceso de innovación constante, que se materializa en productos concretos y no teóricos. Para llegar a esta sociedad, Drucker tuvo que desvalorizar, primero, la teoría de Marx y, a continuación, al pensamiento antiguo y a su educación, la Paideia griega y la humanitas romana. Esto permite que el trabajador adquiera cada vez mayor poder sobre los capitalistas, pues el saber está de su lado. Con ello, quedan conjuradas tanto la lucha de clases como la posibilidad de una sociedad comunista, que habría previsto Marx, pues se conformaría ahora una novedosa sociedad de clases en torno a la tecnología, en la que la clase obrera ha superado a la capitalista.

Sobre la hipótesis de que la sociedad que Drucker describe, a pesar suyo, no es sino la misma sociedad capitalista que quiere superar con su teoría, hablaremos, ahora, del concepto de educación en Herbert Marcuse, con el que también enfrentaremos concepciones como la de Drucker, enajenantes e inhumanas. En esta confrontación teórica, siguiendo a Marcuse, la forma de la educación antigua, la humanitas, resurge con peso fundamental y se dirige, no sólo contra planteamientos teóricos, como el de Drucker, sino, en general, contra la actualidad liberal y su proceso educativo en particular. 


\section{A. Planteamiento del Problema: la "lucha por la existencia" Y el individuo} LIBERAL

En su Marcuse $\left(1986^{2}\right)$, ese autor se refiere centralmente a la educación como formación subjetiva. Esta formación se realiza contraponiéndose, según él, al sentido que el capitalismo liberal da a las necesidades: el de "lucha por la existencia". Este sentido capitalista es dotado de valores por parte del Estado, el trabajo enajenado y la educación. Precisamente, la explicación de esta "lucha por la existencia", Ileva a Marcuse a un concepto de educación con perspectiva humana. Pero, para llegar a esa perspectiva, cruza primero por lo público capitalista: el Estado.

En una sociedad dominada por la "lucha por la existencia", afirma Marcuse: "no podemos esperar una exigencia popular de una educación así ni el respaldo y el apoyo desde arriba." (Marcuse, 1986: 44). Esta tesis de Marcuse tiene relación con lo que Marx (1977: 32 y ss.) señala sobre la intervención del Estado en la educación. En ese lugar, Marx afirma que el Estado sólo debe proporcionar recursos financieros y materiales y no debe involucrarse en la enseñanza y aprendizaje, pues influye de manera decisiva en el proceso de "enajenación" desde la educación, y que ésta última tiene un lugar fundamental en la vida humana cotidiana y en el presente de cada individuo. El Estado influye en ese sentido de enajenación, por una parte, mediante programas educativos y la imposición de modelos de desarrollo social, sobre el supuesto de que deben atenderse las demandas sociales eficiente y eficazmente. Estas demandas, no se refieren a necesidades naturales (comer, beber, etc.), sino que se reflejan en determinadas aspiraciones (tener un coche, ropa, etc.), que son las que primordialmente le dan dirección al proceso productivo. Siguiendo esta perspectiva, para Marcuse el Estado participa en este proceso de enajenación al dirigir a una sociedad desde la economía, como en la época del "Estado de bienestar", pues impulsa y fortalece el sentido de esas aspiraciones y, de esa manera, también al proceso productivo. El Estado establece un orden al que protege mediante leyes que también crea y opera de manera ad hoc, incluso para que ese orden se convierta en una cultura, para lo cual, ahora, influiría en los procesos educativos de manera institucionalizada. Según Marcuse, ese orden que el Estado impulsa mediante la economía y la educación, establece la reproducción y la formación de una cultura de la escasez, que no es sino un proceso de fortalecimiento del dominio del "reino de la necesidad" que es a lo que responde la "lucha por la existencia".

En el capitalismo liberal, según Marcuse, la educación es complemento en el "cambio del contro/ sobre el proceso productivo". Este control, se explica en dos hechos que se unen dialécticamente: "trabajo enajenado" e "individualidad creadora". La educación contribuye en el sentido social actual que el liberalismo da a toda actividad humana. Este sentido se origina en las necesidades del proceso productivo mismo (y desde aquí es posible iniciar la "corrección" a teorías como la de Drucker):

\footnotetext{
${ }^{2}$ Esta obra compila los siguientes trabajos de Marcuse publicados en diferentes fechas y lugares: "El individuo en la Gran Sociedad", pp. 7-52; "Notas para una nueva definición de la cultura", pp 53-89; "La liberación de la sociedad opulenta", pp. 91-118; "La dialéctica y la lógica después de la segunda guerra mundial", pp. 119-147, y "La ideología de la muerte", pp. 149170. En adelante, sólo me referiré al número de página del libro y no a cada uno de esos trabajos de Marcuse.
} 
la educación debe convertirse en fuente de riqueza. Con esta esencia, la educación participa en la creación de una cultura de la productividad impulsada por las necesidades y dirigida a contribuir en la estructuración de una sociedad de escasez. En este propósito, se une al "trabajo enajenado" que participa en esta estructuración social y que adopta dos formas: primero, la de progreso técnico, segundo, la de las necesidades de la productividad.

En cuanto progreso técnico, el "trabajo enajenado" tiene un doble efecto esencial: contribuye al fortalecimiento de la "lucha por la existencia", por una parte y, por otra, pone las condiciones para el apaciguamiento de esta. Atrapado en esta contradicción, el progreso técnico impulsa un hecho ambiguo: la cultura de la escasez y la de la productividad. En la conformación de esta cultura ambigua, el progreso técnico produce el engaño histórico que consiste en hacer creer que la productividad es la principal vía de satisfacción de necesidades. Pero, según Marcuse, por el contrario, la productividad liberal es creadora de cada vez más necesidades e intensifica las existentes, imponiendo, así, la sociedad de escasez y el "reino de la necesidad", según el planteamiento de Marx (2008) y, de esta manera, el "trabajo enajenado", en la forma de productividad liberal impone la cultura de la "lucha por la existencia". Este progreso técnico capitalista, tiene, por otra parte, el ingrediente del valor de la libertad, que Marcuse quiere entender como aquel que hace del individuo un ser no necesitado, apaciguado de esa "lucha por la existencia", pues el progreso técnico posibilita la producción de la suficiente riqueza para ello. Pero, para Marcuse, eso sólo sería posible cambiando el sentido de la productividad, ya que el capitalismo liberal, con la creación de nuevas necesidades y la intensificación de las existentes, estructura constantemente relaciones sociales con individuos que se identifican como productores y consumidores, presos del "reino de la necesidad". Este hundimiento en ese "reino", constituye, según Marcuse, la primera característica del trabajo enajenado.

La segunda característica de este "trabajo enajenado", al que se apega la educación del capitalismo liberal, se conforma cuando el individuo queda preso en las necesidades de productividad, convirtiéndolas en el punto de referencia de la vida humana, y fundando, así, un mundo productivista. A este cautiverio contribuyen fundamentalmente dos hechos: 1) la apropiación del llamado "tiempo libre" por parte del productivismo moderno capitalista y 2) el dominio de lo socialmente determinado sobre el individuo, al entregarse este último a la jornada laboral. El "tiempo libre", según Marcuse, es una creación del liberalismo capitalista y tiene, en este sentido, una doble esencia jurídica: luego de cumplir con una jornada laboral, el individuo tiene derecho a un "tiempo libre". De esta manera, ese tiempo aparece como parte del disfrute de las libertades a las que el individuo tiene derecho, liberándose de las obligaciones del proceso de trabajo inmediato, pero, en la medida en que es concebido como tiempo de reposo para el trabajo, en ese tiempo libre en realidad, el individuo continúa ligado a la jornada laboral. Se forma, además, una cultura en la que el individuo aparece como si perteneciera a esa jornada, incluso, llega a identificársele socialmente con su actividad productiva, como alguien que cumple una labor productiva para la sociedad. De esta manera, el trabajo sigue estando socialmente determinado y poniendo en cuestión la individualidad de las personas. Se cumple, así, la segunda característica del "trabajo enajenado" según Marcuse. 
Esta caracterización del "trabajo enajenado", como proceso de cautiverio en el "reino de la necesidad", fundado por el progreso técnico y la productividad, es ya un proceso de formación del individuo moderno por parte del capitalismo liberal. Pero la educación institucionalizada, agrega a este proceso de formación dado por el "trabajo enajenado" una consciencia en los individuos, que construye mediante una instrucción en determinadas "normas de conducta" que, en esta sociedad -según Marcuse- regularizan las aspiraciones del individuo. Esas reglas sociales se dirigen a la determinación de los procesos productivos y de los productos en cantidad y en calidad necesarias, para responder a la demanda social, a la que los individuos ya cautivados por el "trabajo enajenado", se ven obligados a responder.

El capitalismo liberal, sin embargo, le promete al individuo ser libre y hasta egoísta. Pero, para que esta libertad individual sea verdadera, en el sentido de que el individuo se apropia de sí mismo, según Marcuse, se requiere de una autonomía que sólo la creatividad puede otorgarle: imponer al proceso productivo sus propias reglas, ya sea como productor, ya como consumidor. Marcuse ejemplifica esta posibilidad de autoapropiación del individuo, con la creación artística. Lo que impulsa la creatividad del artista, son sus propias necesidades, sentimientos y sentidos, y sólo depende de sus habilidades y capacidades, desligándose, así, de lo socialmente determinado y contraponiéndose al productivismo liberal. Al lograr esta separación, la sociedad productivista lo considera inútil e improductivo, pero su utilidad reside en otro ámbito, al de los sentimientos humanos. El capitalismo liberal productivista, responde a esta subversión imponiendo, de nuevo, el sentido de la escasez. La educación aporta a esta respuesta liberal, cultivando a los individuos en la idea de que una educación de "calidad", es la que desarrolla sus capacidades y habilidades, incluso sus sentimientos, para satisfacer las necesidades de la sociedad a la que deben pertenecer.

Pero, a pesar de esta misión que le impone la sociedad liberal, la de complementar al "trabajo enajenado", el "productivismo" y el "reino de la necesidad", según Marcuse, la educación puede ser útil a la formación de un "clima intelectual para el surgimiento de nuevas necesidades individuales", que pueden contener el germen de la oposición al orden que les dio origen y sentido, impulsando a los individuos a que exijan a "los poderes, públicos y privados, que financian la educación", el cumplimiento de las promesas de implementación de mecanismos para la satisfacción de esas necesidades y el apaciguamiento de la "lucha por la existencia". Esto podría gestar un conflicto cualitativo con "la sociedad existente", pero esta es la naturaleza dialéctica de la educación; la subversión al orden existente, precisa de concebir toda actividad individual como humana, y en este punto, Marcuse llega al planteamiento ético como formación de valores.

\section{B. LA EDUCACIÓN COMO SUBVERSIÓN HUMANA: LA EMERGENCIA DE LA HUMANITAS}

Para que la educación sea subversiva al orden que le dio origen (el capitalismo liberal), debe dar al individuo herramientas que impulsen lo que es propiamente humano: la creatividad con base en necesidades, sentimientos y sentidos humanos, es decir, una 
cultura que ejemplifica el artista ${ }^{3}$. Por su parte, el capitalismo liberal impulsa una contra posición a esa esencia humana, al crear una sociedad abstracta que demanda y determina una creatividad convertida en productividad. Es necesario, entonces, precisar una definición de lo humano, por una parte, y de lo social, por el otro, sobre la base de la contraposición de productividad y creatividad. Marcuse lo lleva a cabo, poniendo en el centro de su argumentación el concepto de lo humano.

Marcuse define lo humano partiendo de lo social: los seres humanos, dice, son quienes "[v]iven en una sociedad". Por el contrario, el liberalismo, haría de lo social, en primer lugar, una abstracción, pues, mediante el productivismo, en realidad, lo social toma distancia de los individuos, primero, imponiéndoles necesidades que les son ajenas -no trabajan para ellos, sino para lo social-y, segundo, trabajan sólo para obtener un salario. Con ello, en segundo lugar, se cumple el engaño a los individuos que consiste en nombrarlos libres y sociales a la vez, pues son hundidos en un productivismo ciego, en el que son despojados de su pertenencia a lo social y del producto destinado a satisfacer necesidades humanas. Con este despojo, se crea en el individuo una cultura dotada de una regularidad con principios y valores cuyo sentido es la "lucha por la existencia" (Marcuse, 1986: 17).

La contraposición a esta cultura productivista liberal, en educación, para Marcuse sería aquella que va "de acuerdo con la idea de humanitas", para lo cual se requiere de un sentido del deber, es decir, de una ética, diferente (Marcuse, 1986: 45). En este sentido, el productivismo liberal se debate contra la humanitas en el valor de la justicia ${ }^{4}$, que en Marcuse aparece como una lucha entre cuantitivismo y cualitativismo (Marcuse, 1986: 46). El productivismo liberal, según Marcuse, canaliza ese valor a través de la política (Estado y democracia ${ }^{5}$ y la ciencia (como progreso técnico), y con la educación le da establece como algo normal y como la única posibilidad de vida en sociedad, traduciendo la justicia en algo cuantificable y positivista, en concordancia con una práctica tecnológico-productivista capitalista matematizada y cuantificable (Marcuse, 1986: 40, 41, 71 y 73).

Para Marcuse el problema no es la ciencia matematizada y cuantificable, sino el sentido que le da el orden social moderno que sub-valora lo cualitativo como lo que efectivamente satisface necesidades humanas, pues su prioridad no es la satisfacción

\footnotetext{
${ }^{3}$ Habermas, 2001, cree que la primera "teoría crítica" (en la que se incluye a Marcuse), sigue a un Marx que abreva del Hegel del Sturm und Drang, que ve en el arte la superación del capitalismo. Según Habermas, superando ese aspecto romántico se mostrarían las implicaciones revolucionarias del planteamiento crítico. Hasta lo que llevamos, esta observación de Habermas no contraría el planteamiento crítico de Marcuse.

${ }^{4}$ Marcuse se refiere aquí a Kant, pero no significa que abandone su marxismo, sino que recupera del pensamiento crítico original, su apego a un humanismo particular, que es el que a continuación se expondrá en este artículo. Para el tema de la identidad entre moral y humanidad en la tradición kantiana, cf. Cortina y Conill, 1994, Cortina, 1986 y 2008.

${ }^{5}$ Nusbaum (2015), detalla efectos específicos de una educación "economicista" liberal sobre la democracia. Wallerstein (2011) sintetiza de manera brillante la contradicción entre liberalismo y democracia. cf., también, Todorov (2014).
} 
de esas necesidades. De esta manera, el liberalismo sub-valora la relación armónica del individuo con lo objetivo, entendido como lo "otro que sí mismo" y adopta, así, su esencia anti-social. La posición humanista, por oposición, prioriza lo cualitativo sobre lo cuantitativo, y concibe a éste último al servicio del primero, pues persigue la satisfacción efectiva de necesidades y aspiraciones humanas desde el origen: el proceso creativo libre. Se opone al "trabajo enajenado", propio del capitalismo liberal, mediante un proceso de apropiación humana constante, al que la educación puede contribuir, haciendo conciencia de y elevando a valor fundamental esta humanidad creativa. La justicia humanista, entonces, se mide según las necesidades y las capacidades individuales, que alimentan a lo sociedad cualitativamente.

De esta manera, el sentido humano que Marcuse opone al capitalismo liberal, defiende al individuo real, cuyo "saber" se fundamenta en la creación humana descrita y que se aplicaría a toda producción individual. Con esta teoría -sin proponérselo, al menos explícitamente- Marcuse se contrapone a Drucker, pues el "saber", está destinado, no a la tecnología, sino al ser humano, que emerge en ese proceso creativo como principio, objetivo y fin de la producción. Este individuo crea, así, una identidad diferente, no objetiva o relativa a los objetos, sino subjetiva o relativa a los humanos.

Al contribuir con la formación de una cultura que se erige sobre la base de la humanización del individuo descrita anteriormente, la educación se contrapone al capitalismo liberal en la vida cotidiana y en la institución escolar. La escuela, según Marcuse, ha sido el lugar de concentración de los individuos con fines políticos, desde su esencia como espacio institucional y público. Desde esta esencia estatal, se imponen en ella determinados sentidos y valores, que reducen la educación al "aprendizaje" para la formación de un sujeto que el capitalismo liberal dirige hacia el productivismo mercantil, con una cultura del sacrificio, como parte fundamental de la "lucha por la existencia". Por este camino, Marcuse nos lleva a una conclusión fundamental y contraria a lo que Drucker ha propuesto: la educación ha de darse en la "experiencia de la humanitas."

\section{EDUCACIÓN TÉCNICA, HUMANITAS Y TRANSVALORACIÓN}

En un escrito sobre Max Weber, Marcuse había tratado el tema del incumplimiento de la promesa capitalista liberal de que con el "progreso técnico", se alcanzaría una vida mejor. En esos escritos critica la racionalidad de la "conciencia industrial moderna" (Marcuse, 1970: 117-140), que crea una cultura automatizada, mecánica (Storey, 2008), y desarrolla una ideología que, ligada a las necesidades empresariales, lleva incluso a la educación para la guerra (Noble, 2011).

Por su parte, con un concepto de humanitas, Marcuse plantea la humanización del progreso técnico desde la educación tanto la que se da en la vida cotidiana como la que se adquiere en la escuela. Con esta tesis, aunque la humanitas no es un tema que Marcuse desarrolle específicamente, es posible encontrar ese concepto en los fundamentos de su obra. Por otra parte, Marcuse está atento a que su planteamiento sobre educación no se contraponga al de Marx, en particular el que éste hace sobre la educación técnica, en el cual el sentido humano es difícil de percibir con claridad (Manacorda, 2007). 
En Marcuse encontramos a la humanitas, primero, como un proceso educativo que se opone al pensamiento operativista. Este operativismo es propio de la especialización que también aparece en el pensamiento científico como ciencias naturales, sociales y del espíritu o humanidades. En esta división moderna del pensamiento, Marcuse considera que sólo las humanidades hacen evidente la humanitas, en "modos de pensar, de imaginación, de expresión esencialmente no operacionales y trascendentes" y con "valores personales, emocionales, metafísicos y poéticos" que conforman un "universo de conductas" que son indispensables a la humanitas (Marcuse, 107: 163). Así, el análisis de la humanitas, se da en la diferenciación entre pensamiento operativo y no operativo.

La esencia no operativa de la humanitas ligada a lo que hoy en día reconocemos como humanidades es histórica. Según Marcuse, la humanitas apareció y se formó en la pre-modernidad y es amenazada por el liberalismo capitalista por el carácter operacional que el productivismo le da a la humanidad. Es posible que, en la primera parte de esta afirmación, Marcuse atienda las lecciones de su primer maestro: Martin Heidegger, quien en su Heidegger (1954, p. 153) afirma que la humanitas es la traducción romana de la Paideia griega (y que es, muy probablemente, a lo que se refiere negativamente Drucker, como vimos en el primer apartado de este artículo). Esta humanitas se opone al "homo barbarus" y consiste en la educación en las bellas artes en las escuelas filosóficas, y requiere de una concepción que reivindica libertad y realización individuales. Según Heidegger la humanitas aparece cuando el hombre (homo) se pone en cuestión a sí mismo y se torna, así, en humano (humanus), pues demuestra que se preocupa por sí mismo y, al hacerlo, se reconduce a sí mismo a su esencia: medita y cuida ser "humano en lugar de no humano".

Heidegger planteó estas tesis debatiendo con Sartre sobre el concepto de existencia. Con su concepto de "lucha por la existencia", Marcuse expone su intención de superar el planteamiento de Heidegger (Marcuse, 1937: 63 y 75), pues la historia de la humanidad, se desvió por el camino cautivado por las necesidades. Por ello, si bien las humanidades posibilitan poner en evidencia la humanitas, lo hacen superando el "reino de las necesidades" del cual el capitalismo liberal es la forma social más avanzada.

Según Marcuse, con su educación sobre técnicas productivistas, el capitalismo liberal, al contrario de la humanitas, impone una cultura cuantitativista, en la que predominan matemáticas y física. La unidad de ambas asignaturas aparece como entrega del saber a la técnica, como tecnología, otorgándole a ésta última una autonomía que consolida un proceso capitalista de enajenación (Marcuse, 2007: $166)^{6}$. Esta tecnología contiene y promueve una cultura que concibe que sólo lo medible y calculable tiene sentido para el saber y la vida, impulsando, así, en el individuo una valoración y una conducta determinadas sobre el ambiente que le rodea. Una vez cautivado por esa cultura cuantitativista, el individuo se convierte en

\footnotetext{
${ }^{6}$ Marcuse no habla del concepto de subsunción del proceso de trabajo al capital, que puede estar en este hecho que aquí describe desde sus orígenes. Esto es algo que le reclama Veraza (2008: 70): "En El hombre unidimensiona/casi se describe lo que más abajo conceptuaré como subsunción real del consumo bajo el capital, pero los conceptos que usa Marcuse se desvían por completo de esta meta, como si quedaran por detrás de su propia descripción.".
} 
vehículo y promotor de la asimilación y la proyección de esas leyes calculables y cuantificables, que avanzan desde los procesos educativos rumbo a una vida soportada por conductas operativas. De esta manera tiene lugar la aparición de la "razón instrumental", que crea un lenguaje propio, que -como diría Heidegger- es hogar de un determinado Ser y albergue de un determinado ser humano que lo custodia (Heidegger, op.cit.).

La ciencia cuantificable y calculable, lleva a la tecnologización productivista de la vida social, la cual se realiza como proceso de enajenación que consiste en que, en el proceso productivo, el individuo está con herramientas ajenas, incluida la máquina, y con las que va desarrollando sus potencialidades con vistas a una mayor y mejor producción de acuerdo a patrones productivista-cuantitativos determinados socialmente y que condicionan la vida del individuo a que se incorpore a este desarrollo capacitándose en el uso de tecnología con propósitos productivistas. Pero el individuo también tendrá que ser consciente de que el producto de su trabajo no será para él, sino para otros, aquellos que constituyen una sociedad que le demanda productos de determinada cantidad y calidad. Sobre esa base, la cultura y la formación individuales que aquí se imponen, son enajenadas y contrarias a la humanitas como la que Marcuse concibe desde sus orígenes en la Antigüedad, que es la que rechaza Drucker.

La humanitas busca arrancar al ser humano del cautiverio al que lo someten la cultura cuantitativista liberal y el "reino de la necesidad". En este sentido, la humanitas, con actividades no operacionales, busca recrear en el ser humano los valores originales que el capitalismo liberal desvió hacia el "reino de la necesidad" con una cultura de "lucha por la existencia". Esos valores han de ser morales, intelectuales, estéticos (Marcuse, 1965: 190 y 1970: 157). La alternativa que encuentra hoy en día la humanitas es penetrar en la promesa de la civilización tecnológica de crear una vida que alivie la "lucha por la existencia", dar a la educación la misión de y las condiciones para formar individuos efectivamente libres del "reino de la necesidad". Para Marcuse la humanitas no apela a una actividad metafísica, sino a una actividad con sentido humano, opuesto a la especialización capitalista liberal y demandando nuevas posibilidades de existencia. Es contraria a la cultura del sacrificio, a la neutralidad y objetividad de la ciencia que se muestra insensible a la subjetividad y no se preocupa por lo humano, como dice Heidegger.

La humanitas, se traduce en una actividad práctica que posibilita la unidad en el pensamiento, cuida que la actividad científica no dañe al ser humano y en ese sentido se preocupa por el ser humano. No es un humanismo subjetivista en el sentido de que el ser humano está por encima de todo lo existente. Para Marcuse la humanitas que él propone es educación no sólo en las artes y la belleza, también lo es para el descanso y la actividad como proceso de libre creación y no de enajenación. Con esto, Marcuse no se contrapone al señalamiento que hace Marx en el capítulo XIII de El capital, en donde se reconoce que la educación llega a ser un reposo que toma el trabajador una vez que termina la actividad productiva (Marx, 1978: 498n y 535), pero avanza con 
base en la tesis de Marx guiado por la humanitas que, en Marx queda apenas insinuada ${ }^{7}$.

\section{CONCLUSIONES}

Visto desde una perspectiva crítica, como la de Marcuse, el desarrollo tecnológico presenta una dimensión inhumana y otra humana a la vez. La primera es la enajenada, aleja progresivamente el componente humano de lo objetivo y lo remite a la "lucha por la existencia". La dimensión humana del desarrollo tecnológico es contraria a esa enajenación, la tecnología se torna en producto y medio de vida humana. Visto desde la perspectiva del capitalismo liberal, el desarrollo tecnológico sólo tiene una dimensión: el progreso social que prioriza el objetivismo, tanto en la producción de objetos como en la ciencia. Drucker se ubica en esta última perspectiva, aunque de modo inconsciente, enalteciendo al "saber". La adopción de este concepto del "saber" de Drucker lleva, aunque sea de manera inconsciente, a esa vida inhumana y contrahumana. Por su parte, al reivindicar la humanitas, Marcuse, hace recordar que existen otras alternativas de educación y de vida que reproducen el lado humano de esas actividades y procesos, cuyo fin no es la producción y las necesidades, sino los sentimientos de paz, bienestar y sosiego.

\section{BIBLIOGRAFÍA}

ARCOS Fuentes, Israel. (2016). "En torno a la subsunción de la vida en el capital: dominación, producción y perspectivas críticas sobre el capitalismo presente". Oxímora. Revista Internacional de Ética y Política, no 9, pp. 126-145.

CEPAL (Comisión Económica para América Latina y el Caribe). (2018). Hacia una agenda regional de desarrollo social inclusivo: bases y propuesta inicial. Santiago: Naciones Unidas.

CORTINA Orts, Adela. (1986). Crítica y utopía: la escuela de Francfort. Madrid: ed. Cincel.

CORTINA Orts, Adela. (2008). Lo justo como núcleo de las Ciencias Morales y Política. Una versión cordial de la ética del discurso. Madrid: Real Academia de Ciencias Morales y Políticas.

CORTINA Orts, Adela y CONILL, Jesús. (1994). "La responsabilidad social de la empresa y la ética empresarial". Consultado el 16 de agosto del 2017.

\footnotetext{
${ }^{7}$ En el lugar citado, Marx propone que el trabajo se complemente con la educación y la gimnasia. Es muy sugerente seguir el posible significado de esa tesis desde la concepción de educación sobre la que se forma Hegel y tiene el pensamiento alemán desde Herder y Lessing con respecto de la educación humana, cf. Ginzo (2000).
} 
http://www.rlillo.educsalud.cl/Capac_Etica_BecadosAPS/Etica\%20 Organizaciones/Cortina_A.Responsabilidad_social_de_la_empresa.pdf.

DRUCKER, Peter. (1999). La sociedad poscapitalista. Buenos Aires: Editorial Sudamericana.

ECHEVERRÍA, Bolívar. (2006). "El humanismo del existencialismo". Dianóia, no 57 (LI), pp. 189-199.

FERNÁNDEZ Rodríguez, Carlos. (2008). "Management y sociedad en la obra de Peter Drucker". Revista Internacional de Sociología, no 66, pp. 195-218.

GINZO, Arsenio. (2000). Prólogo a Hegel, G.W.F. (2000). Escritos pedagógicos. México: FCE.

HABERMAS, Jürgen. (2001). Teoría de la acción comunicativa: complementos y estudios previos. Madrid: Cátedra.

HEIDEGGER, Martin. (1954). Platons Lehre von der Wahrheit. Mit einem Brief über Den «Humanismus». Bern: Verlag A. Francke Ag.

HESSELBEIN, Frances; DRUCKER, Peter; SNYDER Kuhl, Joan. (2016). 5 claves de Peter Drucker. El liderazgo que marca la diferencia. Madrid: Profit Editorial.

JAY, Martin. (1989). La imaginación dialéctica. Una historia de la Escuela de Frankfurt. Madrid: Taurus.

KORSCH, Karl. (1975). Karl Marx. Barcelona: Ariel.

MAGNET COLOMER, Jordi. (2018). "El análisis de H. Marcuse en torno a la transición del existencialismo filosófico a existencialismo político en el realismo heroico". Res publica. Revista de Historia de las Ideas Políticas, № 21(2), pp. 321-332.

MANACORDA, Mario Alighiero. (2007). Marx e a pedagogia moderna. Sao Paulo: Alínea.

MANSELL, Robin and WEHN, Uta, (eds.). (1998). Knowledge societies: information technology for sustainable development. Oxford University Press, Oxford, UK. Available in LSE Research Online: August 2018 at: http://eprints.Ise.ac.uk/24875/.

MARCUSE, Herbert. (1965). "Remarks on a Redefinition of Culture". Daedalus, 94 (1), 190-207.

MARCUSE, Herbert. (1937). "Über den affirmativen Charakter der Kultur", en MARCUSE, Herbert. (1965). Kultur und Gesellschaft I. Frankfurt am Main: Suhrkamp.

MARCUSE, Herbert. (1970). "Acerca de los fundamentos filosóficos del concepto científico-económico del trabajo", en MARCUSE, Herbert. (1970) Ética de la revolución. Madrid: Taurus.

MARCUSE, Herbert. (1986). Ensayos sobre política y cultura. Barcelona: Planeta Agostini. 
MARCUSE, Herbert. (2007). One-dimensional man. Studies in the ideology of advanced industrial society. New York: Routledge.

MARX, Carlos. (1977). Crítica al Programa de Gotha. Barcelona: Editorial Progreso.

MARX, Carlos. (1978). El capital. Crítica de la economía política. México: Siglo XXI Editores.

MARX, Carlos. (2008). Contribución a la crítica de la economía política. Prólogo. México: Siglo XXI Editores.

MATTICK, Paul. (1985). Marx y Keynes. Los límites de la economía mixta. México: Ediciones ERA.

NOBLE, David. (2011). Forces of production: a social history of industrial automation. New Brunswick, New Jersey: Transaction Publishers.

NUSBAUM, Martha. (2015). "Discurso al recibir el doctorado Honoris Causa por la Universidad de Antioquía, el 10 de diciembre del 2016". Consultado el 17 de diciembre del 2016.2 Parque Explora, http://www.parqueexplora.org/visitenos/noticias/discurso-de-martha-nussbaum-alrecibir-el-doctorado-honoris-causa-en-udeal.

PUELL Palacios, Juan. (2009). "La filosofía de la administración de Peter Drücker". Gestión en el tercer milenio, no 24 (12), pp. 49-53.

ROMERO CUEVAS, José Manuel (ed.). (2016). Herbert MARCUSE, Sobre Marx y Heidegger. Escritos filosóficos (1932-1933). Madrid, España: Biblioteca Nueva.

SARTRE, Jean-Paul. (1973). El existencialismo es un humanismo. Consultado 23 de octubre de 2019, Universidad Complutense Madrid. https://www.ucm.es/data/cont/docs/241-2015-06-16Sartre\%20\%20El_existencialismo_es_un_humanismo.pdf.

STOREY, John. (2008). Cultural Theory and Popular Culture An Introduction. Sunderland, England: Pearson-Longman.

TERRANOVA, Tiziana. (2018). "Marx en tiempos de algoritmos". Nueva Sociedad, no 277, pp. 87-101.

TODOROV, Tzvetan. (2104). Los enemigos íntimos de la democracia. Barcelona: Galaxia Gutenberg.

UNESCO (Organización de las Naciones Unidas para la Educación, la Ciencia y la Cultura). (2005). Hacia las sociedades del conocimiento. Ediciones UNESCO. Consultado el 26 de octubre de 2019, UNESCO, https://unesdoc.unesco.org/ark:/48223/pf0000141908.

UNESCO (Organización de las Naciones Unidas para la Educación, la Ciencia y la Cultura). (2008). Etapas hacia las sociedades del conocimiento. Material de referencia para comunicadores. Montevideo: UNESCO. 
UNESCO (United Nations Educational, Scientific and Cultural Organization). (2015). Student Learning Assessment and the Curriculum: Issues and Implications for Policy, Design and Implementation. Consultado el 25 de octubre de 2019. UNESCO, en http://www.ibe.unesco.org/sites/default/files/resources/ipr1-muskinassessmentcurriculum_eng.pdf.

VERAZA, Jorge. (2008). Subsunción real del consumo bajo el capital. México: Itaca.

VERAZA, Jorge. (2012). Marx y la técnica desde la perspectiva de la vida. Para una teoría marxista de las fuerzas productivas. México: Itaca.

WALLERSTEIN, Immanuel. (2011). Conocer el mundo, saber el mundo: el fin de lo aprendido. Una ciencia social para el siglo XXI. México: Siglo XXI Editores-UNAM. 